\title{
Design and Performance Analysis of Microstrip Patch Array Antennas with different configurations
}

\author{
A. De ${ }^{1}$, C. K. Chosh $^{2}$ and A. K Bhattacherjee ${ }^{1}$ \\ ${ }^{1}$ Dept. of ECE, NIT, Durgapur, West Bengal, India \\ ${ }^{2}$ Dr. B.C Roy Engineering College, Durgapur, W.B, India \\ arnabderocks@gmail.com
}

\begin{abstract}
This abstract demonstrates simple, low cost and high gain microstrip array antennas with suitable feeding technique and suitable dielectric substrate for applications in the $\mathrm{GHz}$ frequency range. The objective of this paper is to design, and fabricate a 16 element rectangular microstrip patch array antenna. Therefore, a novel particle swarm optimization method based on IE3D was used to design an inset feed linearly polarized rectangular microstrip patch antenna array with sixteen elements. .Initially we set our antenna as a single patch and after evaluating the outcomes of antenna features; operation frequency, radiation patterns, reflected loss, efficiency and antenna gain, we transformed it to a $2 \times 1$ array. Finally, we analyzed the $2 \times 2$ array, then $4 \times 2$ array and finally $4 \times 4$ array to increase directivity, gain, efficiency and have better radiation patterns. The simulation has been performed by Zeland software version 14.0 and the desired antenna provides a return loss of $-42.154 \mathrm{~dB}$ at $2.45 \mathrm{GHz}$ by using RT Duroid dielectric substrate with $\epsilon_{r}=2.45$ and height, $h=1.58 \mathrm{~mm}$. The gain of the antenna is found to be $19.455 \mathrm{dBi}$ and the side lobe is maintained lower than the main lobe. Since the resonant frequency of these antenna is around 2- $4 \mathrm{GHz}$, so these are suitable for $\mathrm{S}-$ band applications and can be used in WLAN communication systems.
\end{abstract}

Keywords: Microstrip patch, array antennas, WLAN, IE3D, S-band

\section{Introduction}

In the recent years the development in communication systems requires the development of low cost, minimal weight and low profile antennas that are capable of maintaining high performance over a wide spectrum of frequencies. Microstrip patch antenna is a single layer design which contains mainly these four parts - Patch, Ground plane, Substrate and Feeding part. It is very simple in construction using conventional microstrip line feed. Patch can be given any shape but rectangular and circular configurations are mostly used. Ground Plane can be finite or infinite according to model (Transmission line - model, cavity model, full wave Model or method of moments) used for analysis of dimensions [1-4]. Relative Permittivity $\left(\epsilon_{\mathrm{r}}\right)$ and height $(\mathrm{h})$ are two important characteristics for substrate, Feeding Part can be implemented in these ways Microstrip line, coaxial probe, Aperture coupled and Proximity coupled Feed [5-7]. Single microstrip patch antenna has some advantages (low cost, light weight, conformal \& low profile), but it has little disadvantages too like low gain, low efficiency, low directivity and narrow bandwidth. These disadvantages can be overcome by implementation of many patch antennas in array configuration. As we increase number of patch elements to form an array, improvement in performance is observed. For a rectangular patch, the length $\mathrm{L}$ of the patch is usually $0.3333 \lambda o<L<0.5 \lambda o$, where $\lambda o$ is the free-space wavelength. The height $h$ of the dielectric substrate is usually $0.003 \lambda o \leq h \leq$ $0.05 \lambda o$. The dielectric constant of the substrate $\left(\mathrm{C}_{\mathrm{r}}\right)$ is typically in the range $2.2 \leq \mathrm{C}_{\mathrm{r}} \leq 12$. In order to design a compact Microstrip patch antenna, substrates with higher dielectric 
constants must be used which are less efficient and result in narrower bandwidth. Hence a trade-off must be realized between the antenna dimensions and antenna performance [8$11]$.

\section{Design of a Rectangular Single Element Antenna}

The three essential parameters for the design of a rectangular Microstrip Patch Antenna are:

- Frequency of operation $\left(f_{o}\right)=2.45 \mathrm{GHz}$

- Dielectric constant of the substrate $\left(\epsilon_{\mathrm{r}}\right)=2.45$

- Height of dielectric substrate $(h)=1.58 \mathrm{~mm}$

$>$ The width of the Microstrip patch antenna is given as:

$$
W=\frac{c}{2 f_{\circ} \sqrt{\frac{\left(\varepsilon_{r}+1\right)}{2}}}
$$

Therefore, $\mathrm{W}=46.62 \mathrm{~mm}$

$>$ The effective dielectric constant is given as:

$$
\varepsilon_{r e f f}=\frac{\varepsilon_{r}+1}{2}+\frac{\varepsilon_{r}-1}{2}\left[1+12 \frac{h}{W}\right]^{-\frac{1}{2}}
$$

$$
\text { Where } \begin{aligned}
\varepsilon_{r e f f} & =\text { Effective dielectric constant } \\
\varepsilon_{r} & =\text { Dielectric constant of substrate } \\
h & =\text { Height of dielectric substrate } \\
W & =\text { Width of the patch }
\end{aligned}
$$

Therefore, $\epsilon_{\text {reff }}=2.3362$

$>$ The effective length is:

$$
L_{\text {eff }}=\frac{c}{2 f_{0} \sqrt{\varepsilon_{\text {reff }}}}
$$

$\mathrm{L}_{\text {eff }}=40.056 \mathrm{~mm}$

The length extension is:

$$
\Delta L=0.412 h \frac{\left(\varepsilon_{r e f f}+0.3\right)\left(\frac{W}{h}+0.264\right)}{\left(\varepsilon_{r e f f}-0.258\right)\left(\frac{W}{h}+0.8\right)}
$$

$\Delta \mathrm{L}=0.812 \mathrm{~mm}$

$>$ The actual length is given as:

$\mathrm{L}=\mathrm{L}_{\mathrm{eff}}-2 \Delta \mathrm{L}$

Therefore, $\mathrm{L}=38.432 \mathrm{~mm}$

$>\quad$ Inset fed depth $\mathrm{y}_{0}=11.2 \mathrm{~mm}$. 
Feed width $=5.5 \mathrm{~mm}$.

After optimization we get,

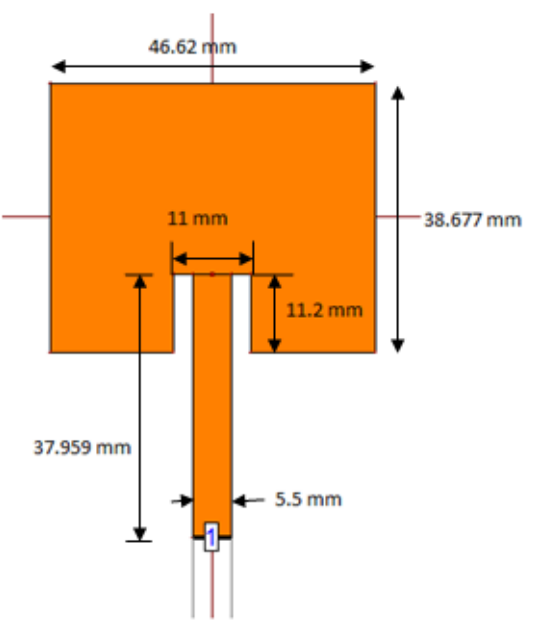

Figure 1. Design of a Single Element Antenna

After optimizing and simulation of the antenna the return loss is found to be -37.1654 $\mathrm{dB}$ at $2.45 \mathrm{GHz}$ and the gain is found to be $6.758 \mathrm{dBi}$ at that resonant frequency with a bandwidth of about $33 \mathrm{MHz}$. The RL plot and the radiation pattern plot is shown below.

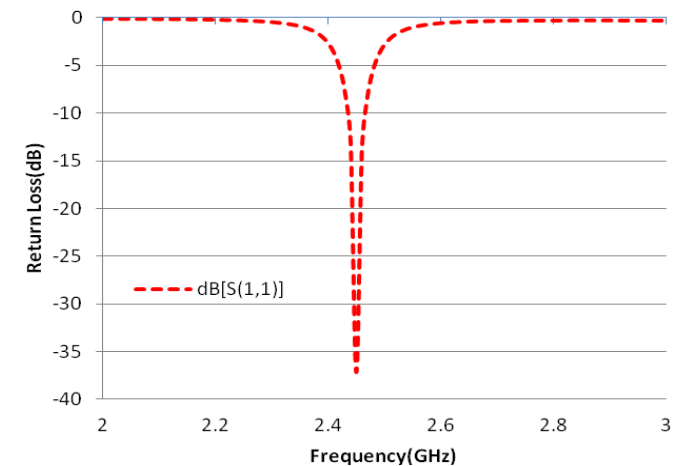

Figure 1(A). Return Loss

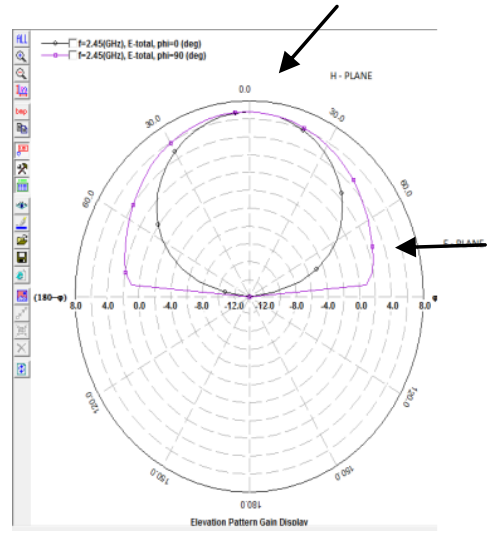

Figure 1(C). 2d Radiation Pattern Plot

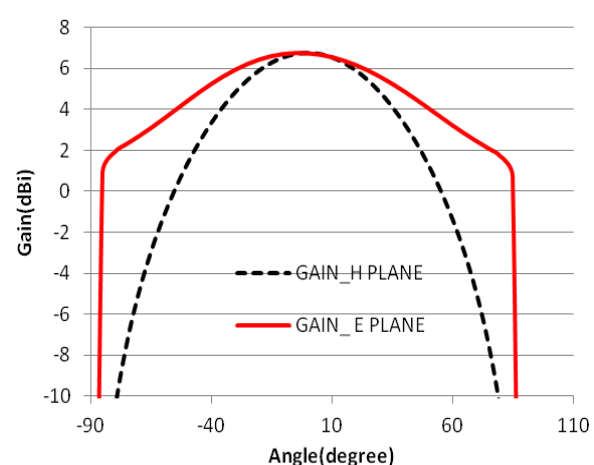

Figure 1(B). Radiation Pattern

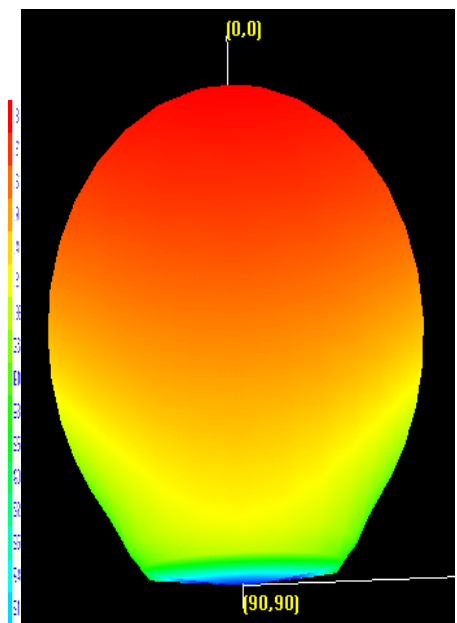

Figure 1(D). 3d Radiation Pattern Polar at $2.45 \mathrm{Ghz}$ 


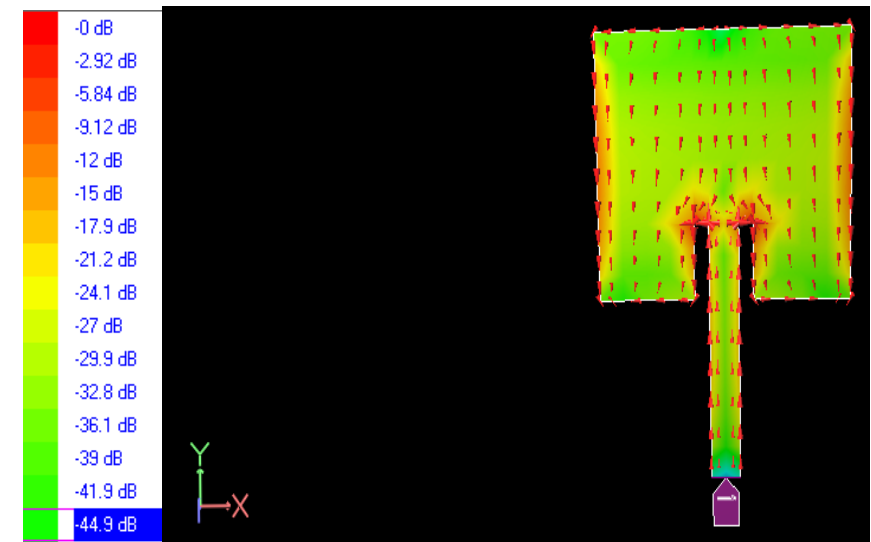

Figure 1(E). Current Distribution Pattern at 2.45 Ghz

\section{Patch Array Analysis}

a) Design and analysis of a $2 \times 1$ array

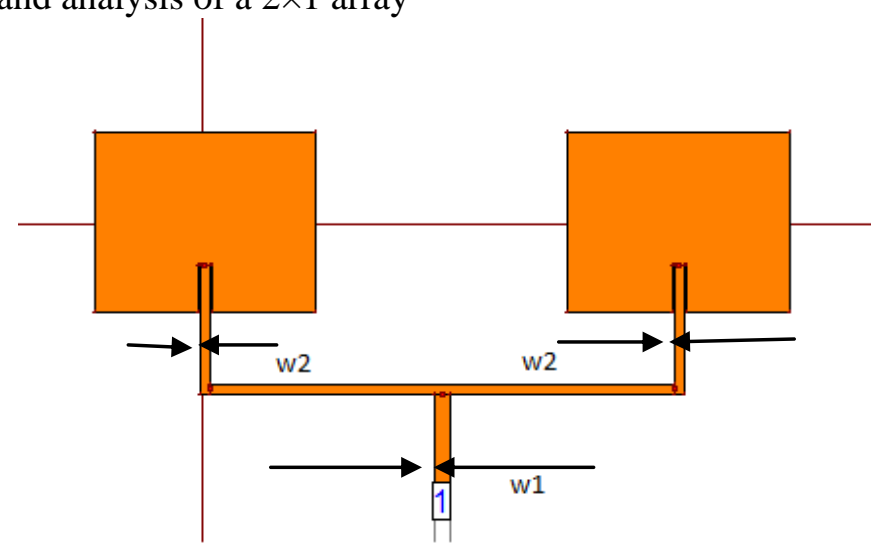

Figure 2. A 2× 1 Array

Here a $2 \times 1$ array is designed with the above said dimensions. Formation of an array requires feeding arrangement with proper impedance matched network (as shown in fig.2).Inset Fed has been used here, dimensions for feeding line are: width (w1) of $50 \mathrm{ohm}$ impedance line is $3 \mathrm{~mm}$ and of $100 \mathrm{ohm}$ (w2) is $2.2 \mathrm{~mm}$.

Here an improved gain of $9.64118 \mathrm{dBi}$ is obtained but consists of side lobes which was not present in the simple single patch. After simulation we get a return loss of $-40.1492 \mathrm{~dB}$ at $2.45 \mathrm{GHz}$.

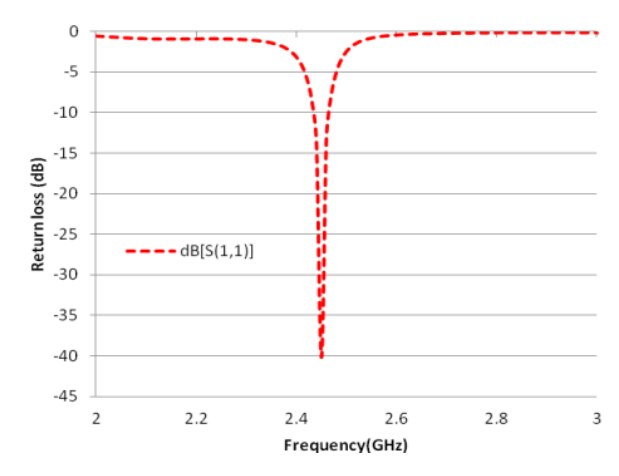

Figure 2(A). S-Parameters Plot

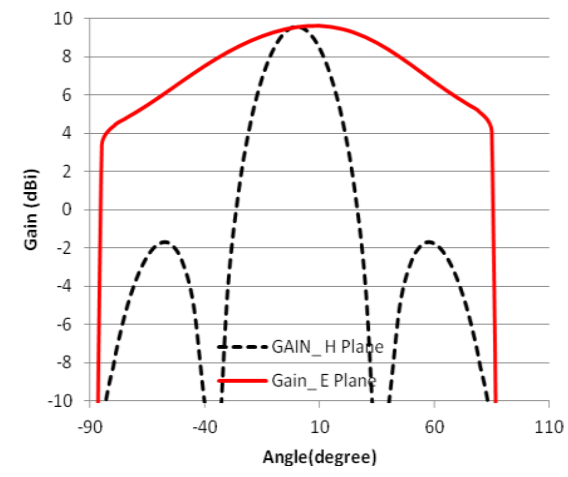

Figure 2(B). Radiation Pattern 


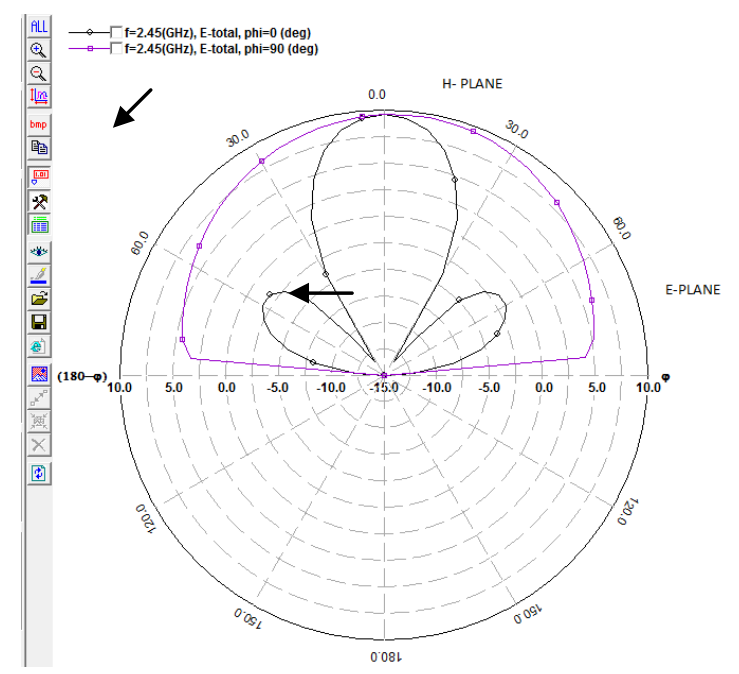

Figure 2(C). 2D Radiation Pattern Polar Plot

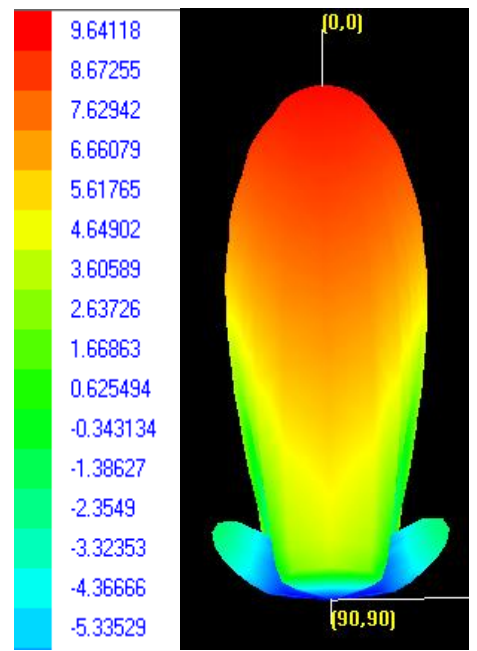

Figure 2(D). 3D Radiation Pattern Plot

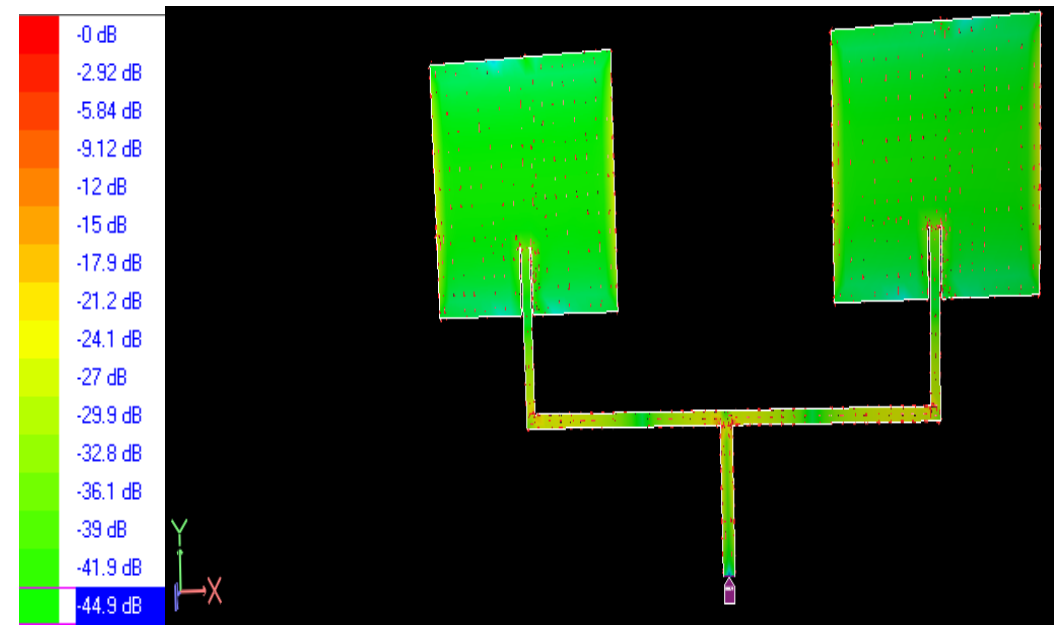

Figure 2(E). Current Distribution Pattern at 2.45 Ghz 


\section{b) Design and Analysis of a $2 \times 2$ Array}

From the previous array we designed an array with 4 elements and the element spacing of $53.88 \mathrm{~mm}$.

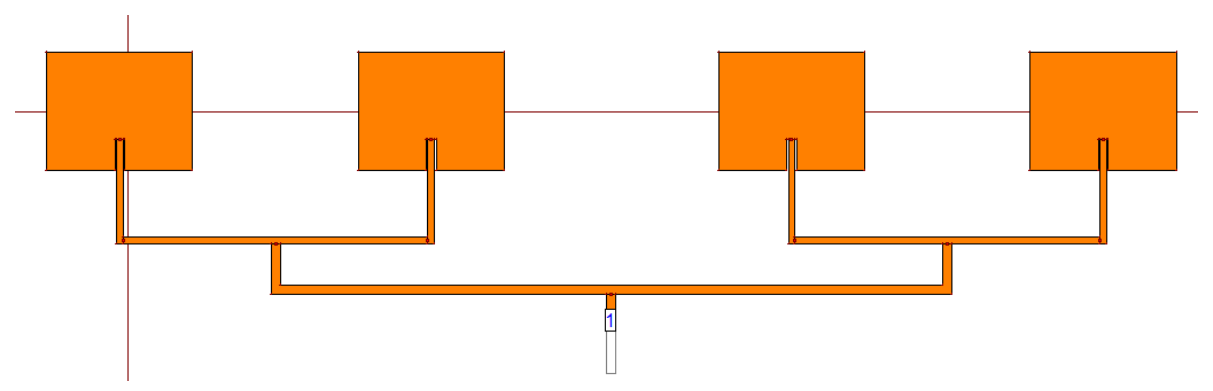

Figure 3. Array with 4 Elements

After simulation we get a Return loss of $-40.1154 \mathrm{~dB}$ at $2.45 \mathrm{GHz}$ with an increased gain of about $12.4062 \mathrm{dBi}$ and improved radiation parameters.

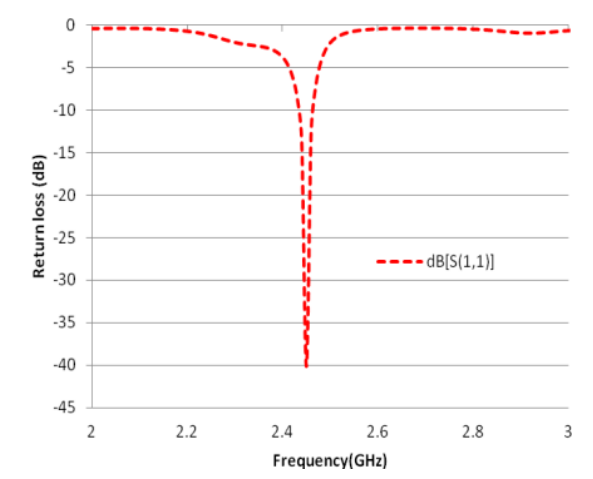

Figure 3(A). S-Parameters Plot

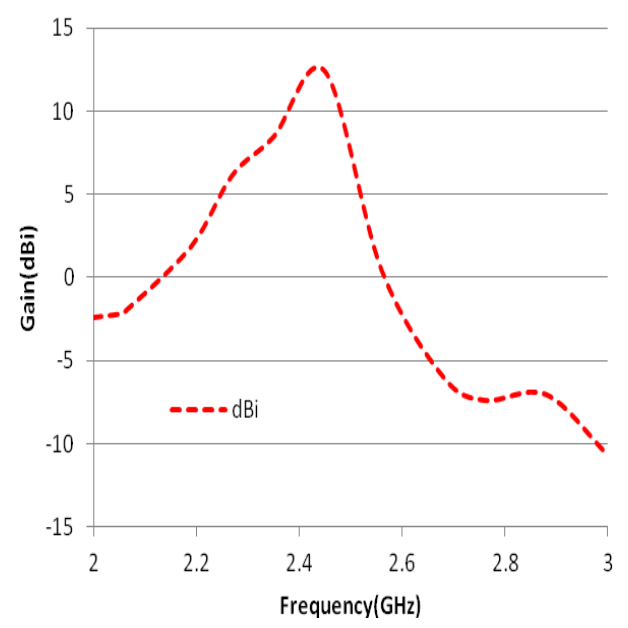

Figure 3(C). Gain vs. Frequency Plot

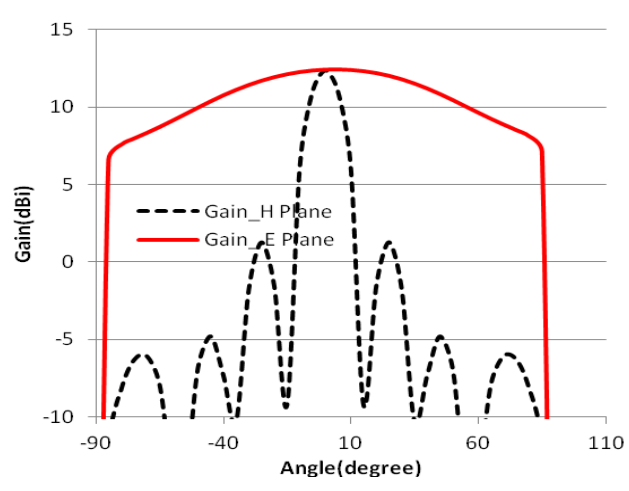

Figure 3(B). 2D Radiation Pattern

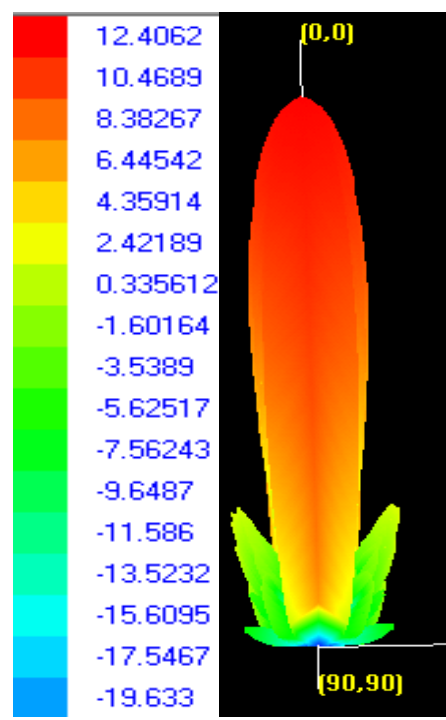

Figure 3(D). 3D Radiation Pattern 


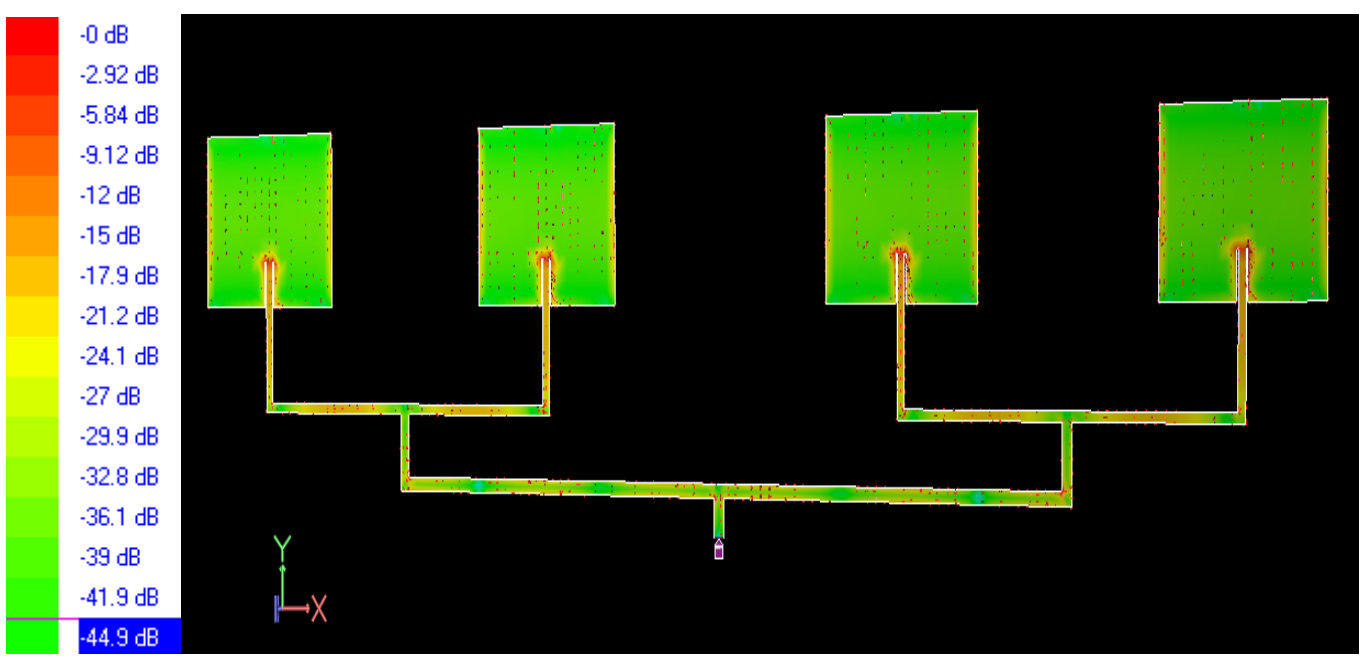

Figure 3(E). Current Distribution Pattern at 2.45 Ghz

c)Design and Analysis of A $4 \times 2$ Array

Now we have designed an array with 8 elements

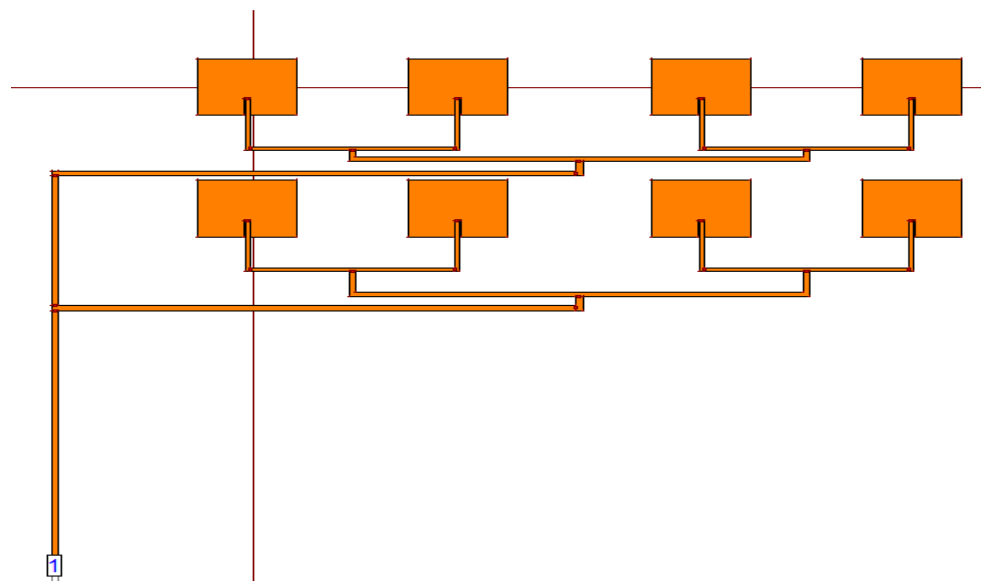

Figure 4. A $4 \times 2$ Array

After simulation at $2.45 \mathrm{GHz}$ we get a gain of about $16.2112 \mathrm{dBi}$ with an increased Directivity of about $17.216 \mathrm{dBi}$ with a Return loss of $-38.045 \mathrm{~dB}$ with a bandwidth of 23 MHz.

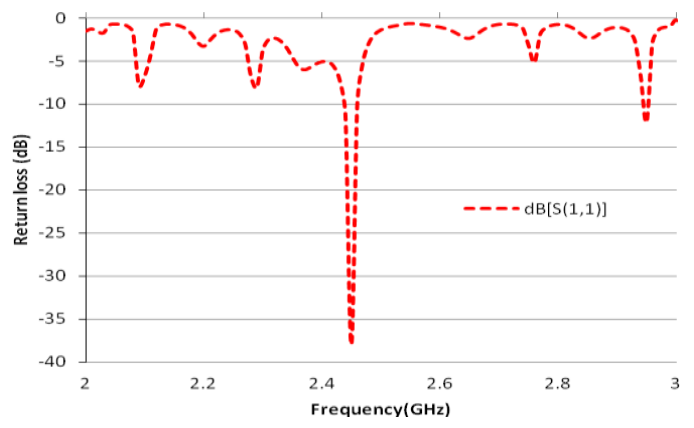

Figure 4(A). S -Parameters Plot

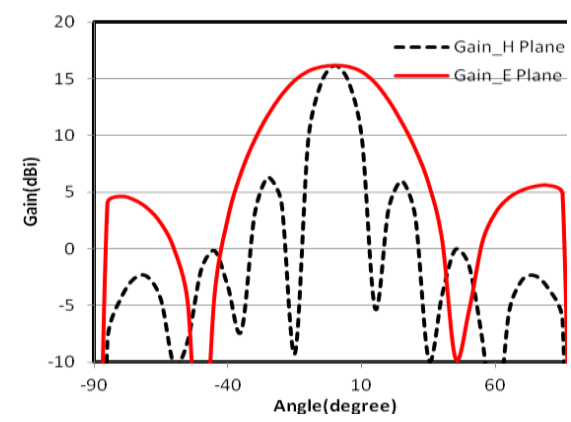

Figure 4(B). 2D Radiation Pattern 


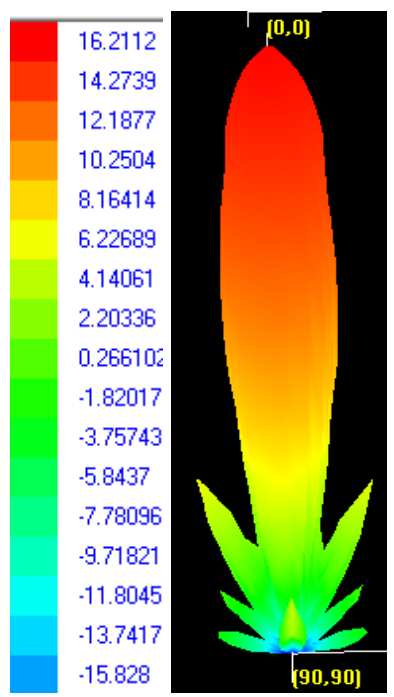

Figure 4(C). 3D Radiation Pattern

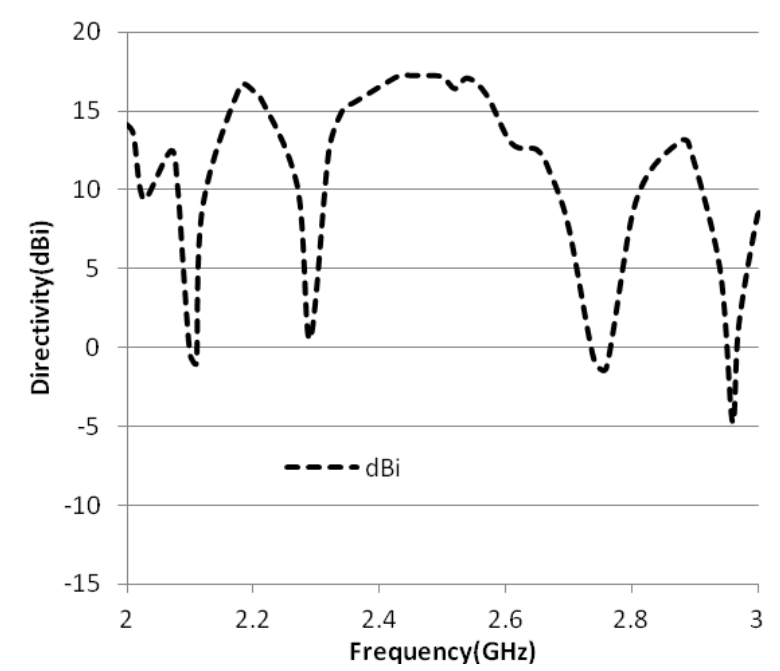

Figure 4(D). Directivity Vs. Frequency Plot

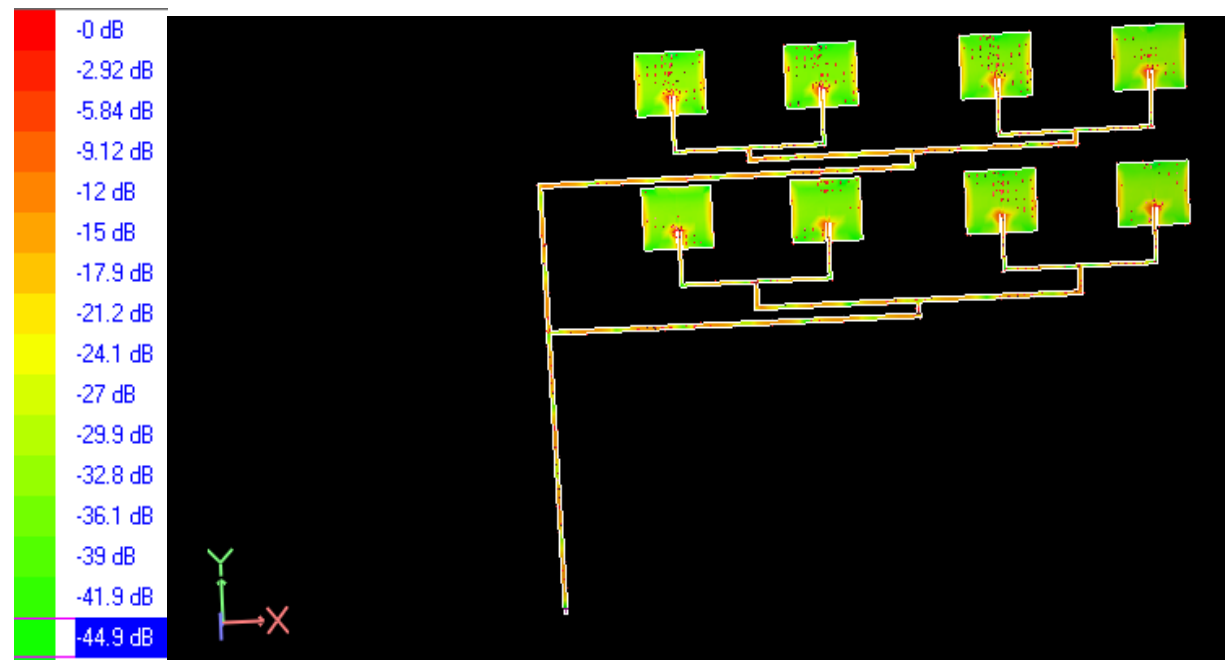

Figure 4(E). Current Distribution Pattern At 2.45 Ghz 


\section{d) Design and Analysis of a $4 \times 4$ Array}

Finally 16 element $(4 \times 4)$ array is designed with corporate type of feed network with feed-width of $3 \mathrm{~mm}$ and feed-length of $17 \mathrm{~mm}$.

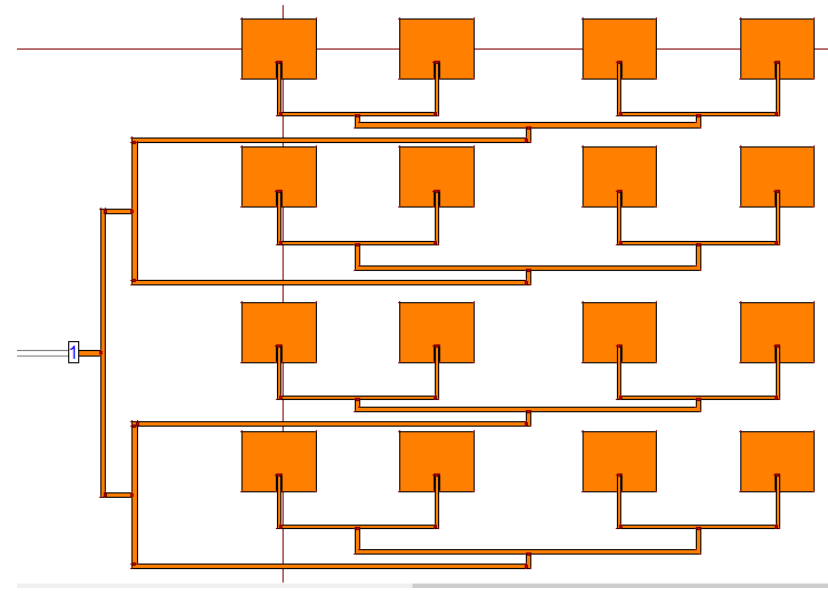

Figure 5A. 16 Element Array

After a no. of simulations we get a Return Loss of about $-42.1538 \mathrm{~dB}$ at $2.45 \mathrm{GHz}$ and an increased gain of about $19.455 \mathrm{dBi}$ and directivity of $20.1971 \mathrm{dBi}$. The antenna and radiation efficiency is found to be $84.3035 \%$ and $84.3086 \%$.

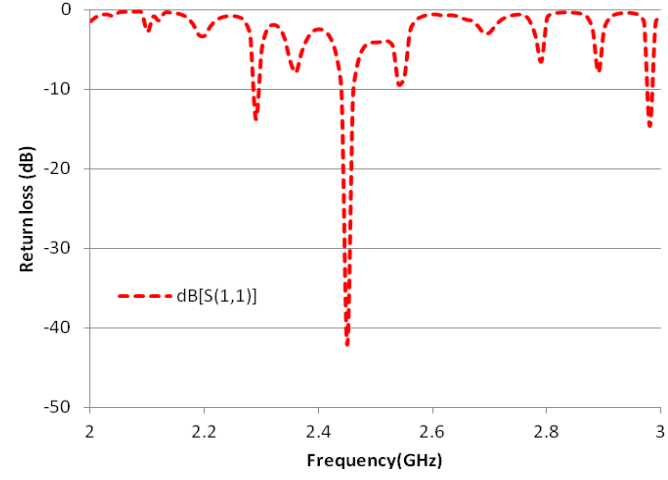

Figure 5(A). S-Parameters Plot

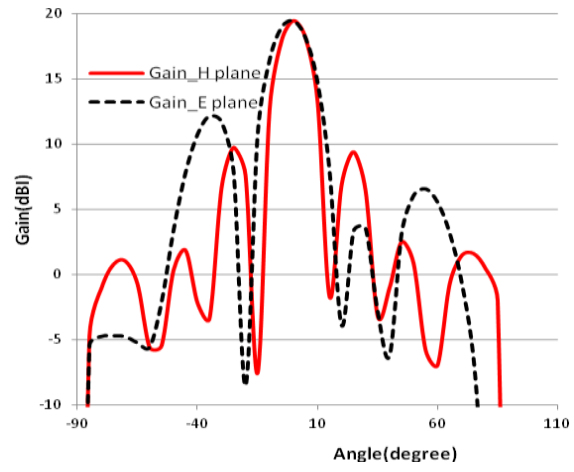

Figure 5(B). 2D Radiation Pattern

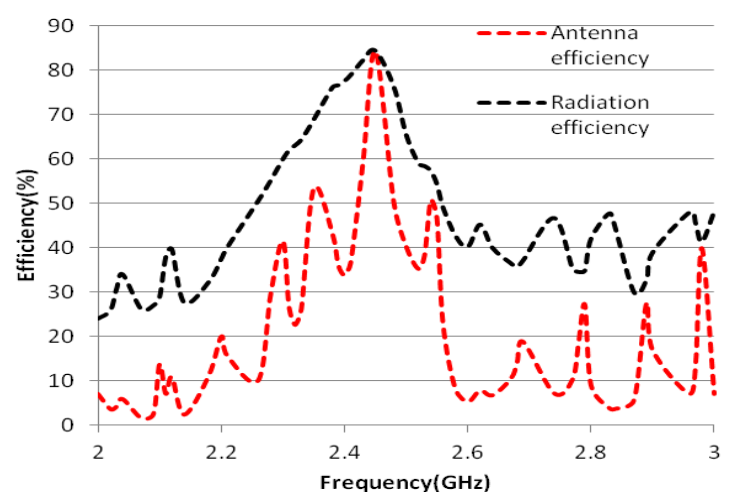

Figure 5(C). Efficiency Vs. Frequency Plot 


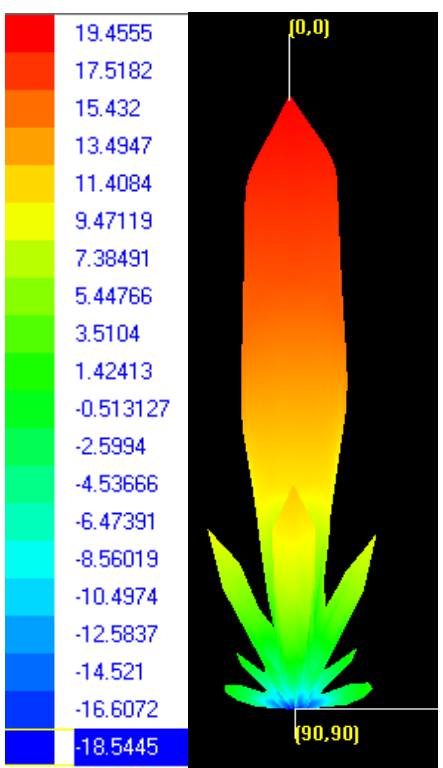

Figure 5(D). 3D Radiation Pattern

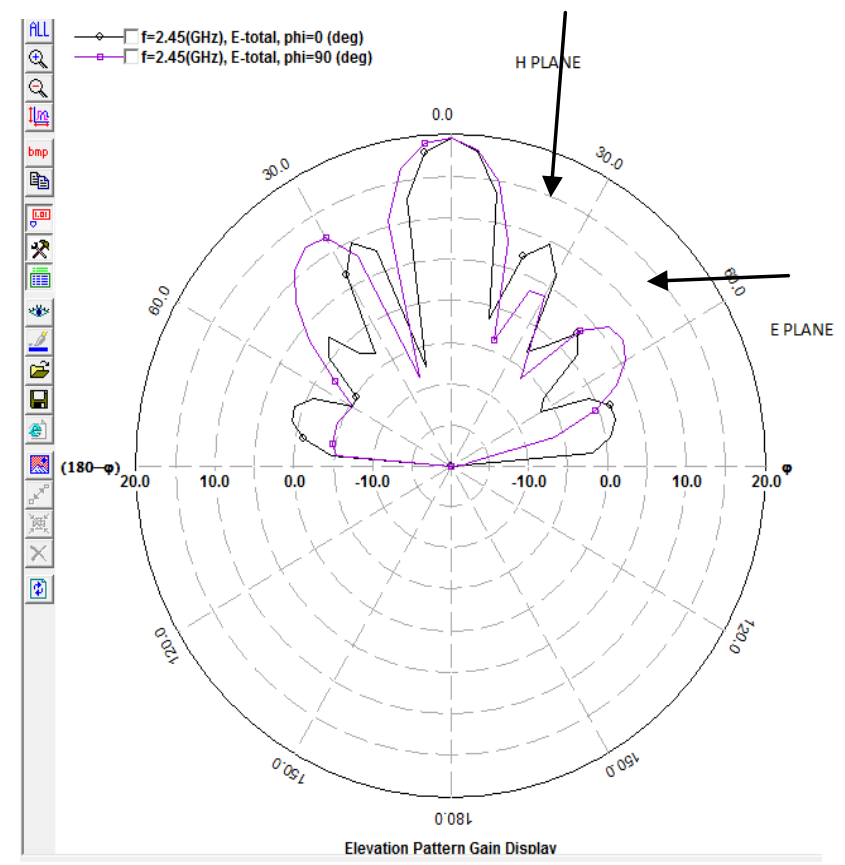

Figure 5(E). 2D Pattern Polar Plot 


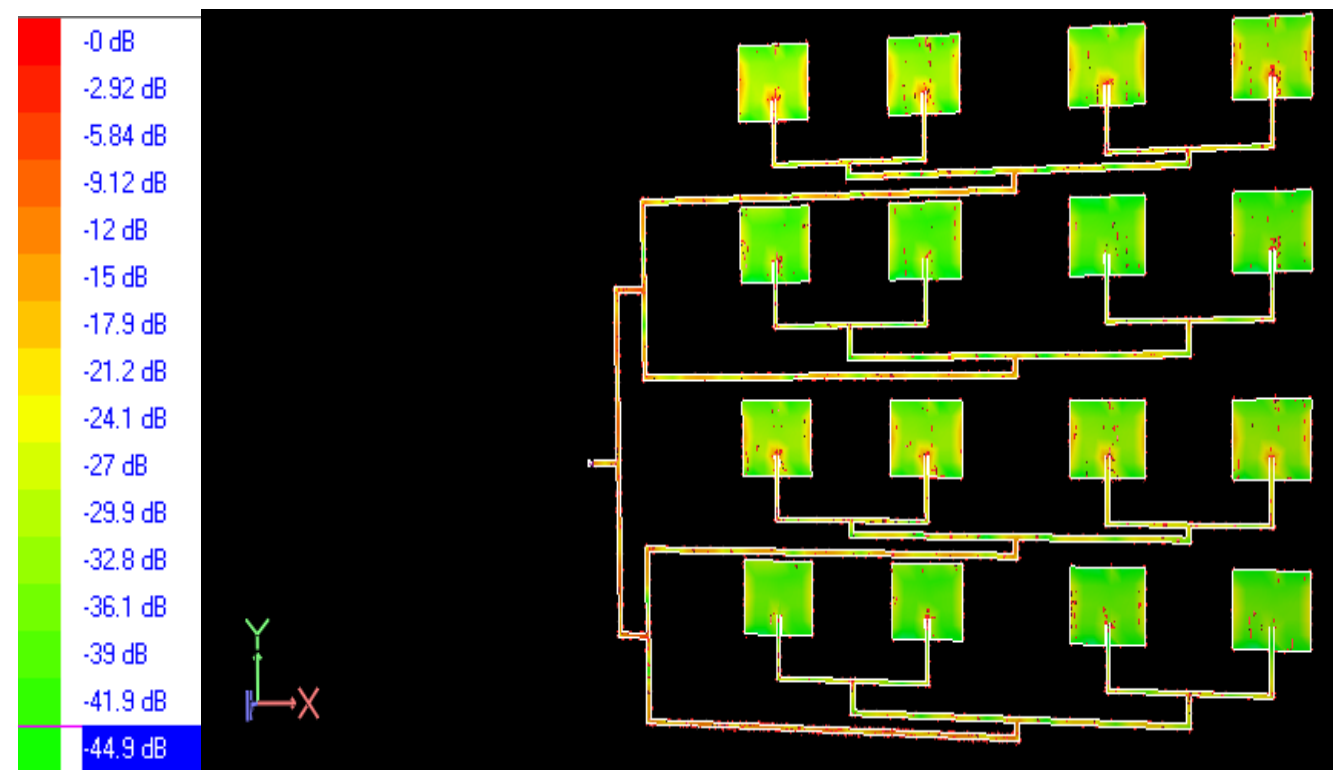

Figure 5(F). Current Distribution Pattern at 2.45ghz

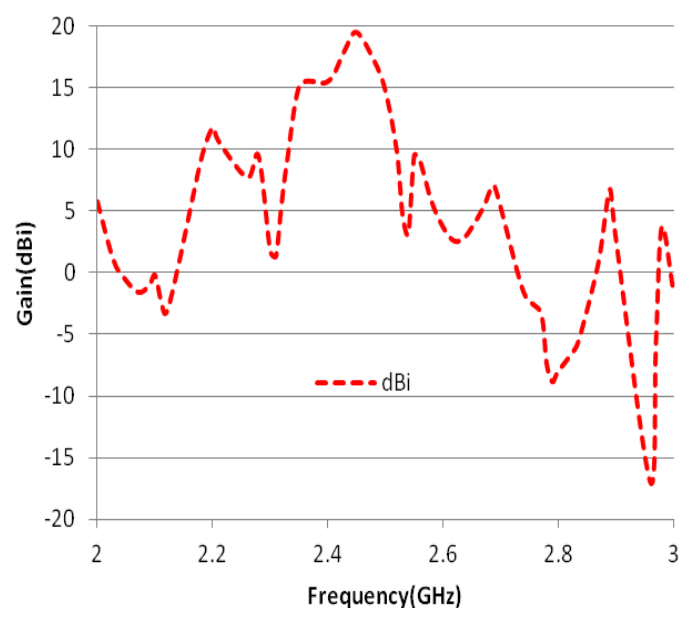

Figure 5(G). Gain Vs. Frequency Plot

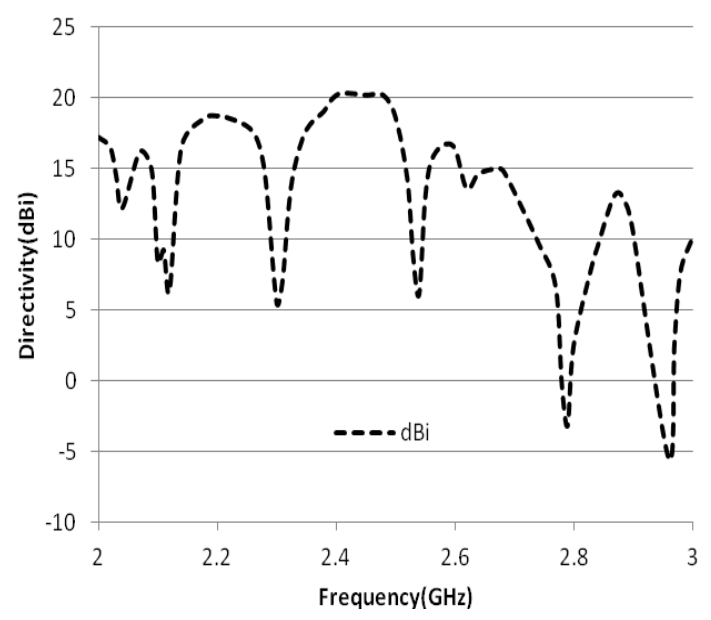

Figure 5(H). Directivity Vs. Frequency Plot 


\section{Comparative Study of All the Designs}

\begin{tabular}{|l|l|l|l|}
\hline ELEMENTS & $\begin{array}{l}\text { RETURN } \\
\text { LOSS(dB) }\end{array}$ & GAIN(dBi) & DIRECTIVITY(dBi) \\
\hline Single & -37.1654 & 6.758 & 7.296 \\
\hline Two & -40.1492 & 9.64118 & 10.3166 \\
\hline Four & -40.1154 & 12.4062 & 13.2624 \\
\hline Eight & -38.045 & 16.2112 & 17.216 \\
\hline Sixteen & -42.1538 & 19.4555 & 20.1971 \\
\hline
\end{tabular}

\section{Conclusion}

From above it is clear that with the increase of the no. of elements, there is an improvement of the antenna radiation parameters like gain, directivity etc. As a future work, we will make comparison between our proposed design for rectangular patch antenna with different design of triangular patch antennas or other shapes and make the array with more elements to provide better radiation efficiency and reduction of mutual coupling by using resonator and reductions in the size. The investigation has been limited mostly to theoretical study due to lack of distributive computing platform. Detailed experimental studies can be taken up at a later stage to find out a design procedure for balanced amplifying antennas. These designed antennas are very simple, cost effective and high efficiency for the applications in $\mathrm{GHz}$ frequency ranges. The optimum design parameters (i.e. dielectric material, height of the substrate, operating frequency) are used to achieve the compact dimensions and high radiation efficiency. The operating frequency of all our designed antennas is about $2.45 \mathrm{GHz}$ which is suitable for $\mathrm{S}$-band applications.

It would also be possible to design an antenna operating in any other frequency bands by changing the design parameters. In future, we will investigate the spiral arrays with different feeding techniques which seem to be having more improved performances for both series feed and corporate feed networks.

\section{References}

[1] R. Garg, P. Bhartia, I. Bahl and A. Ittipiboon, "Microstrip Antenna Design Handbook", Artech House, (2000).

[2] K.F. Lee, "Ed Advances in Microstrip and Printed Antennas", John Wiley, (1997).

[3] D.M. Pozar and D.H. Schaubert, "Microstrip Antennas: The Analysis and Design of Microstrip Antennas and Arrays", IEEE Press, (1995).

[4] F.E. Gardiol, "Broadband Patch Antennas", Artech House

[5] S.K. Behera, "Novel Tuned Rectangular Patch Antenna As a Load for Phase Power Combining", Ph.D Thesis, Jadavpur University, Kolkata.

[6] D.R. Jackson and J.T. Williams, "A comparison of CAD models for radiation from rectangular microstrip patches", International Journal of Microwave and Millimeter-Wave Computer Aided Design, vol. 1, no. 2, (1991), pp. 236-248.

[7] D.R. Jackson, S.A. Long, J.T. Williams, V.B. Davis and K.F. Lee, "Computer- aided design of rectangular microstrip antennas", chapter 5 of Advances in Microstrip and Printed Antennas, John Wiley, (1997).

[8] D.M. Pozar, "A reciprocity method of analysis for printed slot and slot- coupled microstrip antennas", IEEE Transactions Antennas and Propagation, vol. AP-34, (1986), pp. 1439-1446.

[9] C.A. Balanis, “Antenna Theory, Analysis and Design”, John Wiley \& Sons, (1997), New York

[10] H. Pues and A Van de Capelle, "Accurate transmission-line model for the rectangular microstrip antenna”, Proceeding IEEE, vol. 131, pt. H, no. 6, Dec. (1984), pp. 334-340.

[11] W.F. Richards, Y.T. Lo, and D.D. Harrison, "An improved theory of microstrip antennas with applications”, IEEE Transaction Antennas and Propagation, vol. AP-29, (1981), pp, 38-46. 

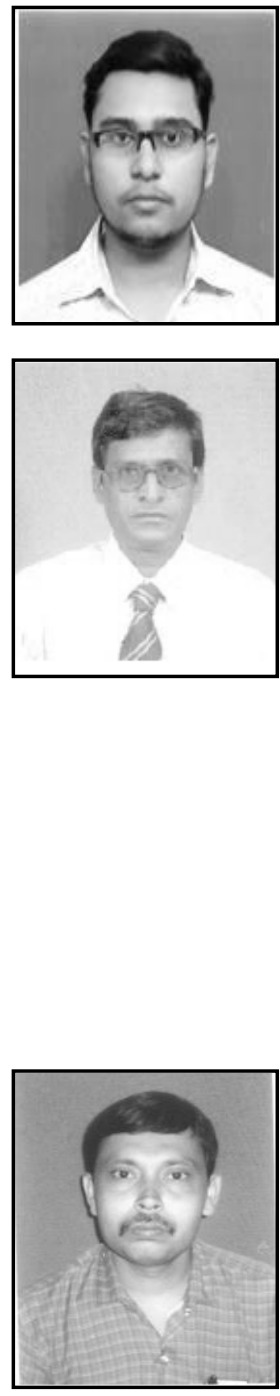

\section{Authors}

Arnab De, He received his M.Tech and B.Tech in Electronics and Communication Engingineering from West Bengal University of Technology in the year of 2012 and 2014 respectively. Now He is working his $\mathrm{PhD}$ degree at National Institute of Technology, Durgapur, India. His Current research includes the Array Antenna and Microwave Devices.

Chandan Kumar Gosh, He receiverd the B.Sc (Hons) degree in Physics and B.Tech degree in Radio physics and Electronics from University of Calcutta in the year 1987 and 1990 respectively. He did M. Tech. degree in microwave Engineering in the year 2003, from Burdwan University, India. From 1991 to 1995, he worked as Development Engineer in Sonodyne Electronics Co. Pvt. Ltd. and from 1996 to 1999 he worked as Assistant Manager (R\&D) in Sur Iron \& Steel Co. Pvt. Ltd. From 2000 to 2009 he was associated with the department of Electronics \& communication Engineering of Murshidabad College of Engineering \& Technology and from August 10 he is in Dr. B. C. Roy Engineering College, Durgapur, India and presently holds the post of Assistant Professor. He published more than 10 contributory papers in reffered journals and the international conferenve proceedings. His current research interests include the Array Antenna, MIMO antenna, DGS and EBG.

Anup Kumar Bhattacharjee, He received his BE in Electronics and Telecommunication Engineering from BE College Shibpur, Howrah in 1983. He received his ME and Ph.D. from Jadavpur University, Kolkata in 1985 and 1989 respectively. Presently he is attached with Electronics and Communication Engineering Department, in National Institute of Technology, Durgapur, and West Bengal, India as a Professor. His area of research is in Microstrip Antenna, Embedded System, and Mobile Communications. Fourteen number of $\mathrm{PhD}$ successfully awarded under his guidance. 
International Journal of Future Generation Communication and Networking Vol. 9, No. 3 (2016) 